\title{
Major Congenital Anomalies: A New Rising Tide of Concern to the Health System
}

\author{
Salwa Al Ubaidani ${ }^{1}$, issa al salmi ${ }^{1}$, Mouza Al Salmani ${ }^{1}$, Badriya Al Fahdi ${ }^{1}$, and Suad \\ Hannawi $^{2}$ \\ ${ }^{1}$ The Royal Hospital \\ ${ }^{2}$ MINISTRY OF HEALTH AND PREVENTION
}

May 6, 2020

\begin{abstract}
Introduction: WHO has considered Major Congenital Anomalies (MCA) as a recognizable cause of morbidity and mortality in infants and children under five years of age. Method: This is a descriptive study of antenatal MCA over 10 years period from January 2009 to December 2018. All data were analyzed statistically using STATA software (Stata Corporation, College Station, TX). Results: During the study period, there were 147563 patients. Of which, 1502 cases found to have major congenital anomalies, among them $947(63.05 \%)$ fetuses with isolated major anomalies and 555 cases (36.95\%) with MCA. The average antenatal prevalence of MCA for 10 years was 10.1 per 1000 pregnancies. The mean gestational age during the first visit was 27(5.5) weeks with range from 10 to 40 weeks. The maternal age was 30 (6.0) years. Coexisting maternal factors were observed in $481(32 \%)$ of patients including gestational diabetes $(8.8 \%)$, maternal age $(6.59 \%)$ and recurrent early pregnancy loss $(7.12 \%)$. Nervous system was the most common (29\%) abnormalities observed and cardiothoracic system (24.9\%) was the second most common. Perinatal outcomes showed that $9.6 \%$ had early neonatal death, $19 \%$ had still births and $4 \%$ had neonatal death. The perinatal mortality rate was $32.6 \%$ among fetuses with major congenital anomalies. Conclusions: The prevalence of major congenital anomalies in our papulation is double the international figures. This study emphasizes the need of national surveillance system and database for congenital anomalies and efforts should be focused in rising awareness of the occurrence and risk factors of congenital anomalies.
\end{abstract}

\section{Manuscript words count 3000}

Number of Tables: 1

Number of figures: 3

\section{Abstract}

Introduction: WHO has considered Congenital anomalies as a recognizable cause of morbidity and mortality in infants and children under five years of age, and it contributes to $7 \%$ of all neonatal deaths worldwide. Knowing the prevalence of birth defects and their trends is important in identifying potential factors that are either causative or preventative. The main aim of the study was to determine the prevalence of major congenital anomalies in a tertiary hospital population, which receives referrals to the Fetal Medicine Unit from all over the country.

Method: This is a retrospective descriptive study of antenatal diagnosis of Major congenital anomalies found in the Obstetrics and Gynecology department, Fetal Medicine Unit, over 10 years period from January 2009 to December 2018.

The study site is a tertiary hospital that is the official referral center for congenital anomalies in Oman, as 
appointed by the Ministry of Health. Data were obtained from the following sources: a registry book for congenital anomalies in Ultrasound and Fetal medicine units, patient information obtained from computerized records at Royal Hospital, records from the labor ward and antenatal clinics. All patients with antenatal diagnosis of major congenital anomalies were included.

Data included demographics, ultrasound findings and other pertinent maternal and fetal information such as maternal age, maternal parity, gestational age at diagnosis, history of consanguinity, coexistence of maternal factors and history of previous fetal anomalies. All data were analyzed statistically using STATA software (Stata Corporation, College Station, TX).

\section{Results:}

During the study period, there were 147563 patients. Of which, 1502 cases found to have major congenital anomalies, among them $947(63.05 \%)$ fetuses with isolated major anomalies and 555 cases (36.95\%) with complex or multiple congenital anomalies. The average antenatal prevalence of congenital anomalies for 10 years was 10.1 per 1000 pregnancies. The mean gestational age during the first visit was 27(SD 5.5) weeks with range from 10 to 40 weeks. The mean (SD) of maternal age was 30 (6.0) years. Most (42.9\%) referrals were from Muscat and 19.4\% from AL Batinah (North) region. Coexisting maternal factors were observed in $481(32 \%)$ of patients including gestational diabetes (8.8\%), maternal age $(6.59 \%)$ and recurrent early pregnancy loss $(7.12 \%)$. Nervous system was the most common $(29 \%)$ abnormalities observed and cardiothoracic system $(24.9 \%)$ was the second most common. Perinatal outcomes showed that $9.6 \%$ had early neonatal death, $19 \%$ had still births and $4 \%$ had neonatal death. The perinatal mortality rate was $32.6 \%$ among fetuses with major congenital anomalies.

Conclusions: The prevalence of major congenital anomalies in our papulation is double the international figures. Early referrals can have a significant impact on early diagnosis, management and counselling. Modifiable maternal risk factors can be prevented and managed effectively during preconception period. This study emphasizes the need of national surveillance system and database for congenital anomalies and efforts should be focused in rising awareness of the occurrence and risk factors of congenital anomalies in Oman and the region of middle East.

\section{Introduction}

In Oman, LBW was $10.2 \%$ out of a total live birth of over 66,000 live birth during 2013 . The worldwide prevalence of low birth weight (LBW) is $15.5 \%$, which amounts to about 20 million LBW infants born each year, $96.5 \%$ of them in the developing countries (1). For example, in Oman, the prevalence of LBW was $4.2 \%$ in 1980, which doubled (8.1\%) in 2000 and has shown a slow but steady increase reaching $10.2 \%$ in 2013 . This also causes an increase in the rate of LBW infants, and subsequently an increased rate of long-term medical sequalae.

LBW has been increasing globally and regionally with various advancement in medical care; including that of obstetric and neonatal care and technological development with restricted growth, and pregnancy complications are taking place as live births.

Recently, over the last few decades, devotion has been steered toward the contribution of the intrauterine environment to the development of chronic and noncommunicable diseases (NCD). Epidemiological studies have demonstrated that a poor intrauterine environment is associated with an increased risk of various non-communicable diseases such as chronic kidney disease, and diabetes (1-5). Many of these diseases may be associated with birth anomalies. Birth defects are an important cause of infant mortality and disproportionately occur among LBW infants.

Congenital anomalies, also commonly referred to as birth defects, are conditions of prenatal origin that are present at birth. Congenital anomalies have a lifelong impact on children's health and survival (6). It is estimated that 1 in 33 newborns have birth defects and it leads to 300000 yearly deaths of neonates (1) and linked to 3.2 million birth related disabilities (7). Congenital anomalies encompass a wide array of structural and functional abnormalities that can occur in isolation (i.e., single defect) or as a group of 
defects (i.e., multiple defects). Multiple defects may occur as part of well-described associations, such as the non-random co-occurrence of vertebral anomalies, anal atresia, cardiac defects, trachea-esophageal fistula, and/or esophageal atresia, renal and radial anomalies, and limb defects (VACTERL) (8,9). Such disabilities can impose social stigma and economic burden on poor families, society and health care organizations (6). Cardiac system, neural tube defects and Down syndrome are most common type of anomalies seen (6).

In 2013 the Global Burden of Disease reported that congenital anomalies are one of the top ten causes of mortality in children under five years old (10). Globally, the trend of childhood mortality due to infection and malnutrition is decreasing. This is likely due to the wide availability of vaccination, infection control and improvement in nutrition supply (11). Besides, the availability of standard pediatric and maternal health services, the contribution of congenital anomalies upon mortality and morbidity of neonates is on the rise (12). Early diagnosis of congenital anomalies in antenatal period is important for effective counseling, fetal or neonatal timely intervention and termination of pregnancy if needed, planning delivery and future prevention $(13,14)$. The world health Assembly has highlighted the importance of taking actions in prevention diagnosis and timely intervention $(15,16)$.

To deal with the problem efficiently, accurate data is crucial to establish the appropriate methods of surveillance of congenital anomalies (17-20). Accurate estimate on the prevalence and mortality linked to birth defects are limited in low- and middle-income countries in contrast with high-income countries. For instance, in UK, the prevalence of congenital anomalies estimated to be $2-3 \%$ and the 20 -year survival rate is about $85.55 \%$ (21). In United State it is estimated to be 2-3\% (17), 1.07\% in Japan (22), in India $2.5 \%$ (17) and in KSA 52.17 per 1000 pregnancies $(7,23)$. However, government actions and efforts on improving risk factors and primary prevention is more effective when based on accurate data and information gathered about the causes, patterns and outcomes of congenital anomalies $(7,23)$. In this study, we gathered data from the only tertiary hospital for obstetric cases that seen in the Obstetric Ultrasound and Fetal Medicine units, of fetuses with major congenital anomalies, for a duration of 10 years. Main aim was to identify the prevalence, patterns, maternal characteristics and perinatal outcomes.

\section{Methods}

Study setting

This study was conducted at Fetal Medicine Unit of the Obstetrics and Gynecology Department at Royal Hospital. Royal Hospital is the only major tertiary Hospital, Muscat, the capital city of Sultanate of Oman. The institution provides multi specialist care and considered as an official referral center for congenital anomalies in Oman, as appointed by the Ministry of Health.

Pregnant women who followed at obstetric antenatal clinics had a routine anatomy scan between 18 -22 weeks of gestation, patients with high risk can be referred even earlier for first trimester scan, according to the obstetric history and condition. Women with antenatally diagnosed with major congenital anomalies had antenatal follow up with Fetal Medicine Unit. Most patients had two or more ultrasound examinations by fetal medicine senior consultants.

\section{Study design}

This was a retrospective descriptive study of antenatal diagnosis of major congenital anomalies found in the Obstetrics and Gynecology department, Fetal Medicine Unit, over 10 years period from January 2009 to December 2018. Ethical approval for the study obtained from the Scientific Research Committee at Royal Hospital.

Data were obtained from the following sources: a registry book for congenital anomalies in Ultrasound Unit, patient information obtained from computerized records at Royal Hospital, records from the labor ward and antenatal clinics. All patients with antenatal diagnosis of major congenital anomalies were included. Pregnancy outcomes included in the study were live births, Stillbirth (fetal loss at a gestational age of 22 weeks and older), Neonatal death (infant death up to 28 days of life). Perinatal mortality was recorded as fetal demise or neonatal death from 22 weeks of gestation to the 28 th day of infant life. Major congenital anomalies 
were classified according to the system included (Nervous, Cardiothoracic, gastrointestinal, genitourinary, musculoskeletal, anterior abdominal wall defect, hydrops, orofacial, Tumors, Miscellaneous and others).

Data included demographics, ultrasound findings and other pertinent maternal and fetal information such as maternal age, maternal parity, and gestational age at diagnosis, history of consanguinity, coexistence of maternal factors and history of previous fetal anomalies. Antenatal prevalence of congenital anomalies was calculated from the total number of obstetric patients seen. All data were analyzed statistically using STATA software (Stata Corporation, College Station, TX).

\section{Results:}

The number of obstetric patients seen at $\mathrm{RH}$ in the Ultrasound and Fetal Medicine Units were 147563 patients. Of which, 1502 cases found to have major congenital anomalies, among them 947 (63.05\%) fetuses with isolated major anomalies and 555 cases $(36.95 \%)$ with complex or multiple congenital anomalies, during the period of 10 year. Figure 1 shows the progressive rise of number of major congenital anomalies over the years in Oman. The average antenatal prevalence of congenital anomalies for 10 years was 10.1 per 1000 pregnancies.

The mean (SD) of age of study population was 30.22 (SD 6.00) and ranged from (17-50). Most common identified medical history were as follow: diabetes, chronic hypertension, cardiac disease, connective tissue disease, hypothyroidism, epilepsy, iron deficiency anemia, asthma and subfertility.

Table 1 shows the distribution of cases according to regions, frequencies and most frequent organ system identified from each area.

Most (42.9\%) of referrals were from Muscat and 19.4\% from Al Batinah (North) and (17.6\%) cases from South Al Batinah, more details illustrated in figure 2. Among the 11 governorates, cases were mostly referred from Muscat and ALBatinah. From ALWusta region least number of cases were referred with the smallest mean maternal age. AlWusta became a governorate in October 2011, its capital is Hima. It occupies a large area in the middle of Oman and the population density is one of the least comparing to other governorates (5). Many referrals were at 27 weeks (mean 27.47, SD5.5) which was almost consistent across all the governorates.

Coexisting maternal factors were observed in $481(32 \%)$ of patients including diabetes in pregnancy (10.15\%), advanced maternal age $(6.59 \%)$ and recurrent early pregnancy loss $(7.12 \%)$. The consanguinity rate of first cousins was $22 \%$. Two hundred and sixty-two cases (18\%) had a previous family history of similar anomalies.

Of all the major congenital anomalies, the nervous system was the most common (29\%) abnormalities observed and cardiothoracic system (24.9\%) was the second most common. 92 cases presented with Hydrops (6.17\%), out of which $15.2 \%$ cases with Immune Hydrops.

Perinatal outcomes showed that $9.6 \%$ had early neonatal death, $19 \%$ had still births and $4 \%$ had neonatal death. The perinatal mortality rate was $32.6 \%$ among fetuses with major congenital anomalies.

\section{Discussion}

Our study site is a tertiary hospital that is appointed by ministry of health, as an official referral center for congenital anomalies in Oman. Over a decade period of time, there were 147563 obstetric patients seen in the Ultrasound and Fetal Medicine units, of which 1502 cases found antenatally to have major congenital anomalies. The study population is quite young, $>10 \%$ were diabetic, have high consanguinity and a significant previous history of MCA with one third perinatal mortality rate, and majority from the capital area and the coastal region. The average antenatal prevalence of congenital anomalies over 10 years was 10.1 per 1000 pregnancies. The most common anomalies seen in this study were those of the nervous system $(29.2 \%)$, followed by cardiothoracic system. Over the 10 years, the trend of recorded anomalies was fluctuating, recording the highest in 2018 were 11.3 anomalies per 1000 pregnancies and lowest in 2011 (5.2 per 1000 pregnancies).

In the present study, the prevalence of major congenital anomalies was lower compared to two studies were 
conducted in Oman, the first one as an abstract that reported rate of 16.8 per 1000 pregnancies (24). This study was conducted for a period of one year, in a single center which receives only selected cases from limited regions of the country. The second study was an abstract as well, which reported rate of $6.7 \%$, also it was a one-year study representing one regional hospital which receives cases of that region only (25). However, our cases are from all over the country and done over many years to provide a better overall rate of major congenital anomalies.

Many studies from different regions or countries report different anomaly rates, which might be attributed to the diversity in study methods, classifications of birth defects and times of studies $(7,17,19,22,26-28)$. In addition, differences in cultural, genetic, socio-economic elements among studied populations.

Several studies demonstrated an increase rate of birth defects associated with advanced maternal age, especially in females older than 35 years old $(17,26)$. In our study sample, advanced maternal age was one of the common coexisting factors found in our cohort.

In Middle Eastern countries, the prevalence of consanguinity is known to be high. Besides that, important association between consanguinity among couples and increased rate of congenital anomalies has been reported in previous studies $(23,29-33)$. In our study sample, $22 \%$ of mothers were married to their first cousins. Almost consistent with a study was conducted in Oman, which showed about $24.1 \%$ of studied couples married from their first cousins (34).

The burden of congenital anomalies in high risk pregnancies is known to be high (35). Our study described females with bad obstetric history like repeated miscarriages, previous congenital anomalies and perinatal deaths, which might play a role in the development of birth defects in future offspring's, as reported by Sunitha etal. They concluded in her study that females with high risk pregnancy and bad obstetric history found to have double rate (11\%) of congenital anomalies, compared to general population (6\%) (35).

Many epidemiologic studies have illustrated the association between pregestational diabetes (particularly DM type2) and increased risk of specific birth defects in offspring's (36). In our study, the most common coexisting maternal risk was pregnancy with diabetes. This emphasizes the importance of pre-pregnancy counselling and planning with aim of optimal glycemic control for women with preexisting diabetics before they conceive. While the general population risk for having a baby with an MCA is one to three percent, that for a woman who has pregestational diabetes mellitus is three to six times as great. Fetal organogenesis takes place from the fifth to the eighth post-menstrual weeks. A body of evidence suggests that maternal hyperglycemia early in gestation is either contributory to fetal teratogenesis or is a surrogate marker for the causative agent of MCAs in infants of diabetic mothers (37).

As illustrated in figure 1, what can be noticed that, the number of cases diagnosed with congenital anomalies was increasing throughout the years and it is likely due to advancement in ultrasound scan technology, with the utilization of skilled and professional sonographers. Hence, we anticipate an increase in early detection of major congenital anomalies in the coming decade.

Prevalence studies are very beneficial in identifying the baseline rates of congenital anomalies and changes over time. Which is crucial in public health planning and establishment of preventative measures. This study highlights the prevalent nature of antenatal fetal anomalies over a decade of time. Nevertheless, we may have remarkably under-estimated the real incidence of congenital anomalies in the general population. As our hospital is a tertiary health organization, mostly complicated cases are referred, on the other hand, uncomplicated cases may have been followed in other peripheral hospitals.

Early referrals and antenatal diagnoses of major anomalies is crucial for the proper counselling of parents, timely fetal or neonatal intervention, elective termination of pregnancy if needed (38). In addition to that, it helps in planning the delivery in suitable health facility and future prevention. In this study, cases where firstly referred and seen between 10 to 40 weeks of gestation (mean gestational age 27.4 weeks). One case referred early at 10 weeks of gestation, for multiparous women found to have Anencephaly and body stalk anomaly. Early diagnoses enabled timey counselling and elective termination of pregnancy $(23,39)$. 
There are 11 main geographical areas (regions) in Oman, figure 3 (Provincial map of the Sultanate of Oman). Muscat region is the capital city and around $50 \%$ of the population lives there. Al Batinah region contains the largest amount of provenance and was split to Al Batinah North and South. The study showed that majority of referred cases (42.9\%) were from Muscat and Al Batinah, Costal, regions (37.15\% cases), which is expected due to the higher density of population in these areas.

The most common anomalies seen in this study were those of the nervous system (29.2\%), followed by cardiothoracic system. Similar findings were identified in unpublished data from maternal child health unit at ministry of health. Neural tube defects were the most common types of anomalies seen in Nervous system. The dominance and high frequency of neural tube defects in this study was also reported in previous studies in same geographical areas as in Oman Saudi Arabia (7, 23, 29), UAE (40-43), Iran (26, 44, 45), Pakistan $(28,46,47)$ and India $(17,35,48-50)$. Besides, this finding was similar to studies reported by Sawardekar Kiran in 2005, a decade review of major congenital anomalies in Nizwa, Interior provenance, in Oman (51). On the other hand, some countries have reported a decrease in reported incidence of neural tube defects, due to the active intervention in promoting and implement preventative measures, like folic acid fortification in food and supplementation in preconception period (52).

Various randomized trials with other observational studies have illustrated that maternal intake of folic acid with or without multivitamin supplements in preconception period and in early pregnancy could reduce the occurrence and recurrence of neural tube defects (53). In our setting, we need to emphasize more in implementing preventative measures, like food fortification, pre-pregnancy supplementation with effective preconception counselling to emphasize the importance of folic acid and multivitamins intake before planning for pregnancy.

Many increasing evidences showing the link between preconception maternal environmental exposures like tobacco smoke, outdoor air pollution, water with disinfection byproducts, outdoor air pollution and pesticides and elevated risk of congenital anomalies $(52,54)$. In addition, modified maternal lifestyle habits can predispose to the development of congenital anomalies (55). In the present study, $32 \%$ of mothers described to have coexisting maternal factors, the most common one was diabetes in pregnancy (8.8\%). This modifiable risk can be significantly reduced by effective preconception counselling and aiming for a controlled glycemic index before conception.

Congenital anomalies are one of the leading causes of perinatal morbidities and mortalities (52). The perinatal mortality rate in our study was $32.6 \%$ among fetus with major congenital anomalies. This was almost similar to the unpublished data at $\mathrm{MOH}$ (almost $30 \%$ ) and $34.9 \%$ reported in Saudi Arabia $(7,23$, 29). It is important to have further future studies, assessing factors which can affect outcome and survival in neonates born with major birth defects.

\section{Limitations}

Our study was a descriptive retrospective review and might have a bias associated with this type of studies. Some information's we could not retrieve in view of inadequate documentations of characteristics, factors and outcomes. Furthermore, the study may significantly underestimate the real incidence of anomalies in general population, as our sample was from a single tertiary heath organization.

\section{Conclusion}

The important findings from this study indicates the need for birth defect policy to establish a national surveillance system for birth defects. This measure will help in recording of the epidemiology of congenital anomalies, measuring the burden on public health and anticipate the health care needs with the implementation of preconception preventative measures. Currently we have only a notification system at ministry of health and compliance to fill the form is not 100 percent in all the regions and health care centers. Preconception genetic counselling, folic acid fortification and supplement, healthy lifestyle promotion and sufficient nourishment advice can contribute effectively in birth defect prevention programs. Therefore, major efforts are needed to increase awareness of the occurrence and risk factors of congenital anomalies through public 
health education and advocacy.

Funding statement: there was no funding available for the study.

Disclosure of interests: "The authors declare no conflicts of interest" including relevant financial, personal, political, intellectual or religious interests.

Contribution to authorship: SAU, BAF, SH, IAS, and MAS: Conceptualization, Methodology, Software: Data curation, Writing- Original draft preparation. IAS, BAF, MAS and SAU : Visualization, Investigation. BAF, MAS, IAS and SH : Supervision.: IAS and SH : Software, Validation.: IAS, BAF, MAS, SAU and SH: Writing- Reviewing and Editing.

Details of ethics approval: The Scientific Research Committee, at the Royal Hospital, Muscat, has approved the study on $23^{\text {rd }}$ January 2018 with a reference number SRC\#5/2018.

\section{References}

1. Al Salmi I, FA MS, Hannawi S. Birth weight, gestational age, and blood pressure: Early life management strategy and population health perspective. Saudi J Kidney Dis Transpl. 2019;30(2):299-308.

2. Al Salmi I, Hannawi S. Birthweight and Gestational Age: Early Life Management Strategy to Population Health for Non-Communicable Diseases. Int J Pediatr Res. 2018;4(2):9.

3. Al Salmi I, Hoy WE, Kondalsamy-Chennakes S, Wang Z, Healy H, Shaw JE. Birth weight and stages of CKD: a case-control study in an Australian population. Am J Kidney Dis. 2008;52(6):1070-8.

4. Al Salmi I, Hoy WE, Kondalsamy-Chennakesavan S, Wang Z, Gobe GC, Barr EL, et al. Disorders of glucose regulation in adults and birth weight: results from the Australian Diabetes, Obesity and Lifestyle (AUSDIAB) Study. Diabetes Care. 2008;31(1):159-64.

5. White SL, Perkovic V, Cass A, Chang CL, Poulter NR, Spector T, et al. Is low birth weight an antecedent of CKD in later life? A systematic review of observational studies. Am J Kidney Dis. 2009;54(2):248-61.

6. Moorthie S, Blencowe H, W. Darlison M, Lawn JE, Mastroiacovo P, Morris JK, et al. An overview of concepts and approaches used in estimating the burden of congenital disorders globally. Journal of Community Genetics. 2018;9(4):347-62.

7. Sallout B, Obedat N, Shakeel F, Mansoor A, Walker M, Al-Badr A. Prevalence of major congenital anomalies at King Fahad Medical City in Saudi Arabia: a tertiary care centre-based study. Annals of Saudi medicine. 2015;35(5):343-51.

8. DeSilva M, Munoz FM, McMillan M, Kawai AT, Marshall H, Macartney KK, et al. Congenital anomalies: Case definition and guidelines for data collection, analysis, and presentation of immunization safety data. Vaccine. 2016;34(49):6015-26.

9. San Agustin JT, Klena N, Granath K, Panigrahy A, Stewart E, Devine W, et al. Genetic link between renal birth defects and congenital heart disease. Nature Communications. 2016;7(1):11103.

10. Boyle B, Addor M-C, Arriola L, Barisic I, Bianchi F, Csáky-Szunyogh M, et al. Estimating Global Burden of Disease due to congenital anomaly: an analysis of European data. Archives of disease in childhood Fetal and neonatal edition. 2018;103(1):F22-F8.

11. Black RE, Victora CG, Walker SP, Bhutta ZA, Christian P, de Onis M, et al. Maternal and child undernutrition and overweight in low-income and middle-income countries. Lancet. 2013;382(9890):427-51.

12. Pryce JW, Weber MA, Ashworth MT, Roberts S, Malone M, Sebire NJ. Changing patterns of infant death over the last 100 years: autopsy experience from a specialist children's hospital. J R Soc Med. 2012;105(3):12330 .

13. Corsello G, Giuffre M. Congenital malformations. J Matern Fetal Neonatal Med. 2012;25 Suppl 1:25-9. 
14. De Groote K, Vanhie E, Roets E, Ramaekers P, De Wilde H, Panzer J, et al. Outcome after prenatal and postnatal diagnosis of complex congenital heart defects and the influence of genetic anomalies. Prenat Diagn. 2017;37(10):983-91.

15. Baldacci S, Gorini F, Santoro M, Pierini A, Minichilli F, Bianchi F. Environmental and individual exposure and the risk of congenital anomalies: a review of recent epidemiological evidence. Epidemiol Prev. 2018;42(3-4 Suppl 1):1-34.

16. Edmond KM, Quigley MA, Zandoh C, Danso S, Hurt C, Owusu Agyei S, et al. Diagnostic accuracy of verbal autopsies in ascertaining the causes of stillbirths and neonatal deaths in rural Ghana. Paediatr Perinat Epidemiol. 2008;22(5):417-29.

17. Bhide P, Gund P, Kar A. Prevalence of Congenital Anomalies in an Indian Maternal Cohort: Healthcare, Prevention, and Surveillance Implications. PLoS One. 2016;11(11):e0166408.

18. Buehler JW, Strauss LT, Hogue CJ, Smith JC. Birth weight-specific causes of infant mortality, United States, 1980. Public Health Rep. 1987;102(2):162-71.

19. Dolk H, Loane M, Garne E. The prevalence of congenital anomalies in Europe. Adv Exp Med Biol. 2010;686:349-64.

20. Groen H, Bouman K, Pierini A, Rankin J, Rissmann A, Haeusler M, et al. Stillbirth and neonatal mortality in pregnancies complicated by major congenital anomalies: Findings from a large European cohort. Prenat Diagn. 2017;37(11):1100-11.

21. Cassina M, Ruol M, Pertile R, Midrio P, Piffer S, Vicenzi V, et al. Prevalence, characteristics, and survival of children with esophageal atresia: A 32-year population-based study including 1,417,724 consecutive newborns. Birth Defects Res A Clin Mol Teratol. 2016;106(7):542-8.

22. Mezawa H, Tomotaki A, Yamamoto-Hanada K, Ishitsuka K, Ayabe T, Konishi M, et al. Prevalence of Congenital Anomalies in the Japan Environment and Children's Study. J Epidemiol. 2019;29(7):247-56.

23. Sallout BI, Al-Hoshan MS, Attyyaa RA, Al Suleimat AA. Antenatal diagnosis, prevalence and outcome of major congenital anomalies in Saudi Arabia: a hospital-based study. Ann Saudi Med. 2008;28(4):272-6.

24. Al-Dughaishi TR. EP08.03: Prevalence of major congenital anomalies in a tertiary care hospital in Oman (5 years' retrospective study). Ultrasound in Obstetrics \& Gynecology. 2017;50(S1):293-.

25. Al Yaqoubi HN, Fatema N. Prevalence Of Structural Congenital Anomalies, Diagnosed By Prenatal Ultrasound Screening In A Secondary Care Hospital; Oman. Oman Medical Journal. 2018;33(1):86-91.

26. Vatankhah S, Jalilvand M, Sarkhosh S, Azarmi M, Mohseni M. Prevalence of Congenital Anomalies in Iran: A Review Article. Iran J Public Health. 2017;46(6):733-43.

27. Siddika M, Sen S, Islam MN, Bhuiyan MK. Pattern and Risk Factors of Congenital Anomaly in Newborn in a Tertiary Level Private Medical College Hospital, Bangladesh. Mymensingh Med J. 2018;27(4):805-12.

28. Jabeen N, Malik S. Prevalence of Congenital Anomalies and Non-Communicable Diseases in Women of Age 12-75 Years in District Bhimber, Azad Jammu and Kashmir, Pakistan. Iran J Public Health. 2014;43(1):42-9.

29. Al-Alaiyan S, Alfaleh KM. Aborting a malformed fetus: a debatable issue in saudi arabia. J Clin Neonatol. 2012;1(1):6-11.

30. Bromiker R, Glam-Baruch M, Gofin R, Hammerman C, Amitai Y. Association of parental consanguinity with congenital malformations among Arab newborns in Jerusalem. Clin Genet. 2004;66(1):63-6.

31. Bruwer Z, Achandira U, Al Kharousi K, Al-Kindy A. Existing challenges associated with offering prenatal genetic diagnosis in an Arab society in the Sultanate of Oman. J Genet Couns. 2014;23(6):928-32. 
32. Patel PK. Profile of major congenital anomalies in the Dhahira region, Oman. Ann Saudi Med. 2007;27(2):106-11.

33. Zlotogora J, Leventhal A, Amitai Y. The impact of congenital malformations and Mendelian diseases on infant mortality in Israel. Isr Med Assoc J. 2003;5(6):416-8.

34. A. Rajab MAP. Short Report: A study of consanguinity in the Sultanate of Oman. Annals of Human Biology. 2000;27(3):321-6.

35. Sunitha T, Rebekah Prasoona K, Muni Kumari T, Srinadh B, Laxmi Naga Deepika M, Aruna R, et al. Risk factors for congenital anomalies in high risk pregnant women: A large study from South India. Egyptian Journal of Medical Human Genetics. 2017;18(1):79-85.

36. Vinceti M, Malagoli C, Rothman KJ, Rodolfi R, Astolfi G, Calzolari E, et al. Risk of birth defects associated with maternal pregestational diabetes. European Journal of Epidemiology. 2014;29(6):411-8.

37. Negrato CA, Mattar R, Gomes MB. Adverse pregnancy outcomes in women with diabetes. Diabetology \& Metabolic Syndrome. 2012;4(1):41.

38. Groves R, Sunderajan L, Khan AR, Parikh D, Brain J, Samuel M. Congenital anomalies are commonly associated with exomphalos minor. J Pediatr Surg. 2006;41(2):358-61.

39. Verma IC. Burden of genetic disorders in India. Indian J Pediatr. 2000;67(12):893-8.

40. al Talabani J, Shubbar AI, Mustafa KE. Major congenital malformations in United Arab Emirates (UAE): need for genetic counselling. Ann Hum Genet. 1998;62(Pt 5):411-8.

41. al-Gazali LI, Dawodu AH, Sabarinathan K, Varghese M. The profile of major congenital abnormalities in the United Arab Emirates (UAE) population. J Med Genet. 1995;32(1):7-13.

42. Al-Gazali LI, Sztriha L, Dawodu A, Bakir M, Varghese M, Varady E, et al. Pattern of central nervous system anomalies in a population with a high rate of consanguineous marriages. Clin Genet. 1999;55(2):95102.

43. Samson GR. The Incidence and Demography of Neural Tube Defects in Abu Dhabi, United Arab Emirates (1992-1999). Journal of Tropical Pediatrics. 2003;49(4):256-7.

44. Naderi S. Congenital abnormalities in newborns of consanguineous and nonconsanguineous parents. Obstet Gynecol. 1979;53(2):195-9.

45. Tayebi N, Yazdani K, Naghshin N. The prevalence of congenital malformations and its correlation with consanguineous marriages. Oman Med J. 2010;25(1):37-40.

46. Dhaded SM, Somannavar MS, Vernekar SS, Goudar SS, Mwenche M, Derman R, et al. Neonatal mortality and coverage of essential newborn interventions 2010 - 2013: a prospective, population-based study from lowmiddle income countries. Reprod Health. 2015;12 Suppl 2:S6.

47. Gillani S, Kazmi NH, Najeeb S, Hussain S, Raza A. Frequencies of congenital anomalies among newborns admitted in nursery of Ayub Teaching Hospital Abbottabad, Pakistan. J Ayub Med Coll Abbottabad. $2011 ; 23(1): 117-21$.

48. Ara A, Kumar D, Dewan D, Digra NC. Incidence of congenital anomalies in a rural population of Jammu - A prospective study. Indian J Public Health. 2018;62(3):188-92.

49. Das I, Das RN, Paul B, Mandal B, Mukherjee S, Chatterjee U. A study of spectrum of pulmonary pathology and expression of thyroid transcription factor-1 during neonatal period. Indian J Pathol Microbiol. 2018;61(3):334-8.

50. Malik SJ, Mir NA. Perinatal mortality in high risk pregnancy: a prospective study of preventable factors. Asia Oceania J Obstet Gynaecol. 1992;18(1):45-8. 
51. Sawardekar KP. Profile of major congenital malformations at Nizwa Hospital, Oman: 10-year review. Journal of Paediatrics and Child Health. 2005;41(7):323-30.

52. Vrijheid M, Martinez D, Manzanares S, Dadvand P, Schembari A, Rankin J, et al. Ambient air pollution and risk of congenital anomalies: a systematic review and meta-analysis. Environ Health Perspect. 2011;119(5):598-606.

53. Barua S, Kuizon S, Junaid MA. Folic acid supplementation in pregnancy and implications in health and disease. J Biomed Sci. 2014;21(1):77-.

54. Stillerman KP, Mattison DR, Giudice LC, Woodruff TJ. Environmental Exposures and Adverse Pregnancy Outcomes: A Review of the Science. Reproductive Sciences. 2008;15(7):631-50.

55. Yang J, Kang Y, Cheng Y, Zeng L, Yan H, Dang S. Maternal Dietary Patterns during Pregnancy and Congenital Heart Defects: A Case-Control Study. Int J Environ Res Public Health. 2019;16(16):2957.

Table 1

\begin{tabular}{|c|c|c|c|c|c|c|c|}
\hline Region & $\begin{array}{l}\text { Number of } \\
\text { cases }\end{array}$ & Frequency $\%$ & $\begin{array}{l}\text { Mean } \\
\text { maternal } \\
\text { Age }\end{array}$ & Std. Dev. & $\begin{array}{l}\text { Mean } \\
\text { Gestational } \\
\text { Age }\end{array}$ & Std. Dev. & $\begin{array}{l}\text { Most } \\
\text { frequent } \\
\text { System } \\
\text { involved }\end{array}$ \\
\hline Muscat & 642 & 42.97 & 30.66 & 6.013 & 26.79 & 5.736 & $\begin{array}{l}\text { Cardiothoraci } \\
\text { system }\end{array}$ \\
\hline Dhofar & 9 & 0.60 & 27.88 & 5.158 & 28.22 & 6.851 & $\begin{array}{l}\text { Nervous } \\
\text { system }\end{array}$ \\
\hline N. Batinah & 291 & 19.48 & 29.95 & 6.162 & 27.51 & 5.373 & $\begin{array}{l}\text { Nervous } \\
\text { system }\end{array}$ \\
\hline S. Batinah & 264 & 17.67 & 29.79 & 6.406 & 28.21 & 5.111 & $\begin{array}{l}\text { Nervous } \\
\text { system }\end{array}$ \\
\hline N. Sharqiya & 42 & 2.81 & 29.52 & 6.522 & 29.07 & 5.606 & $\begin{array}{l}\text { Nervous } \\
\text { system }\end{array}$ \\
\hline S. Sharqiya & 106 & 7.10 & 30.03 & 5.733 & 28.81 & 3.898 & $\begin{array}{l}\text { Cardiothoraci } \\
\text { system }\end{array}$ \\
\hline Dakhilia & 73 & 4.89 & 30.23 & 4.906 & 27.21 & 6.481 & $\begin{array}{l}\text { Nervous } \\
\text { system }\end{array}$ \\
\hline Dhahira & 51 & 3.41 & 30.19 & 5.106 & 27.96 & 5.153 & $\begin{array}{l}\text { Nervous } \\
\text { system }\end{array}$ \\
\hline Wusta & 2 & 0.13 & 27.5 & 4.949 & 27 & 5.656 & $\begin{array}{l}\text { Genitourinary } \\
\text { Musculoskelet }\end{array}$ \\
\hline Buraimi & 6 & 0.40 & 29.5 & 4.183 & 28.33 & 8.664 & Cardiothoraci \\
\hline Musandam & 8 & 0.54 & 29.12 & 4.015 & 27.25 & 5.897 & Genitourinary \\
\hline
\end{tabular}

Figure 1: shows the progressive rise over the years of major congenital anomalies in Oman 


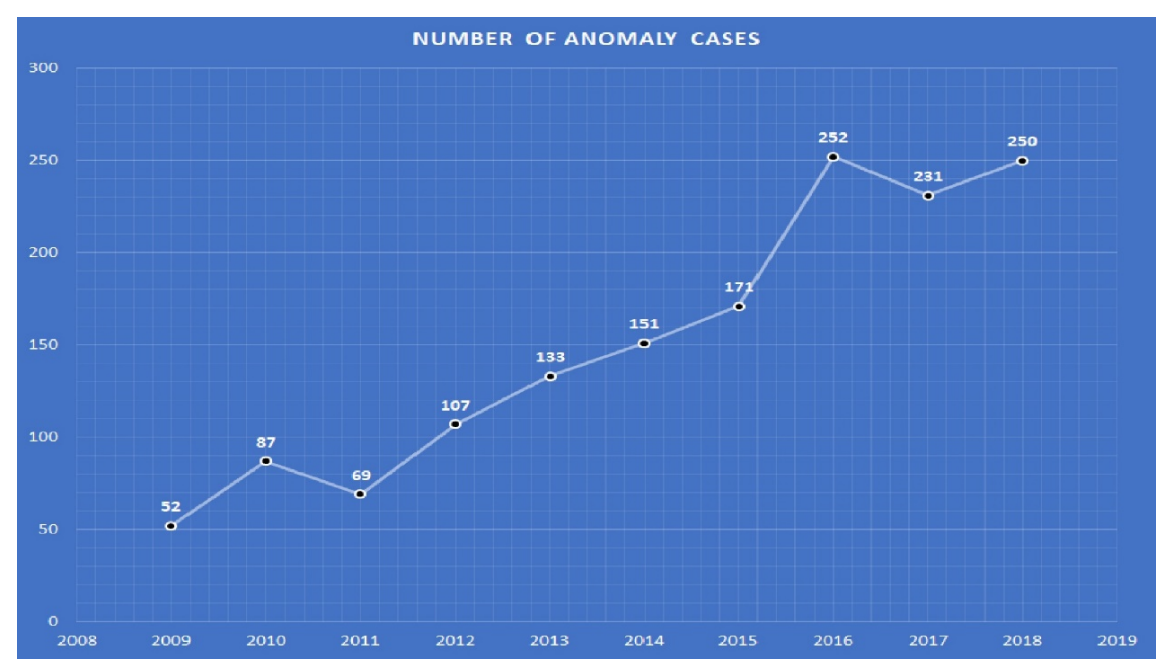

Figure 2; shows the major congenital anomalies by organ system in Oman

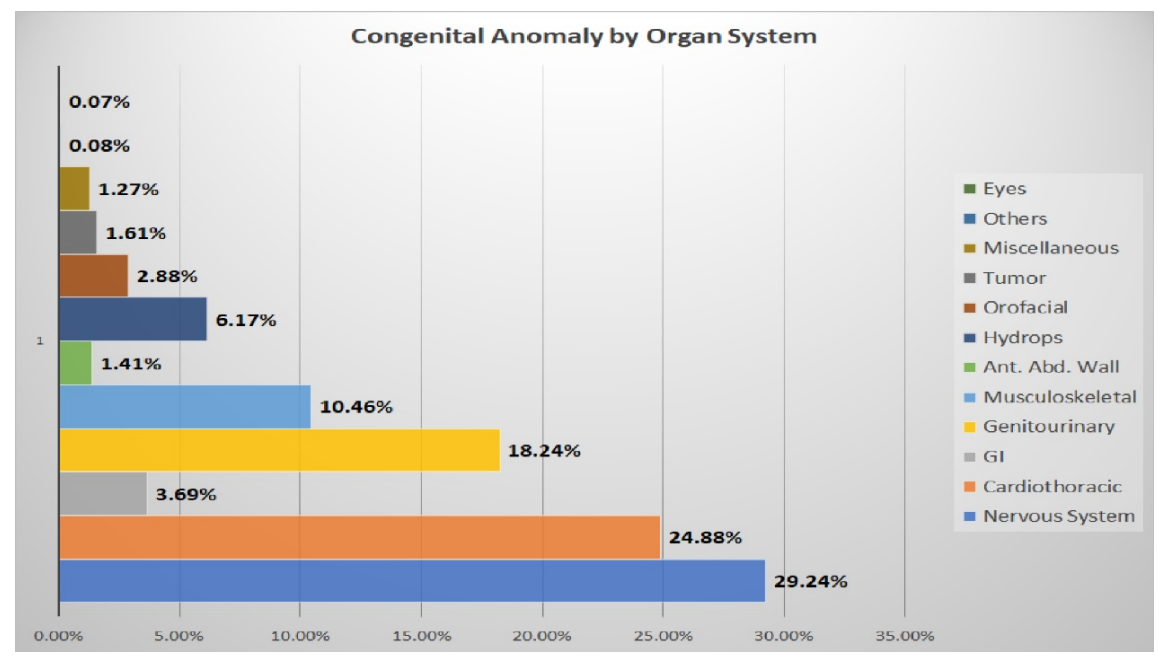

Figure 3: illustrates the various regions of Oman 

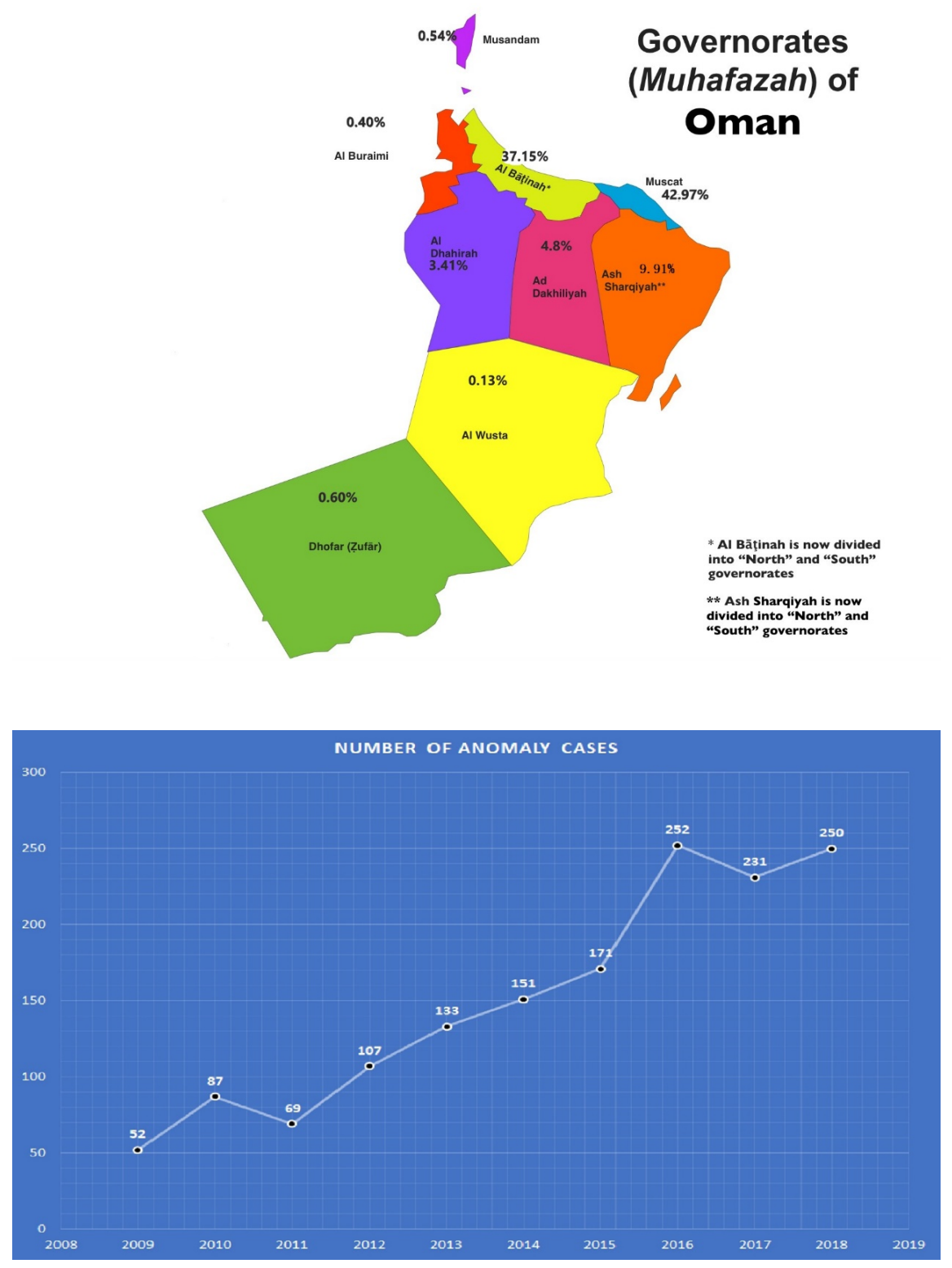

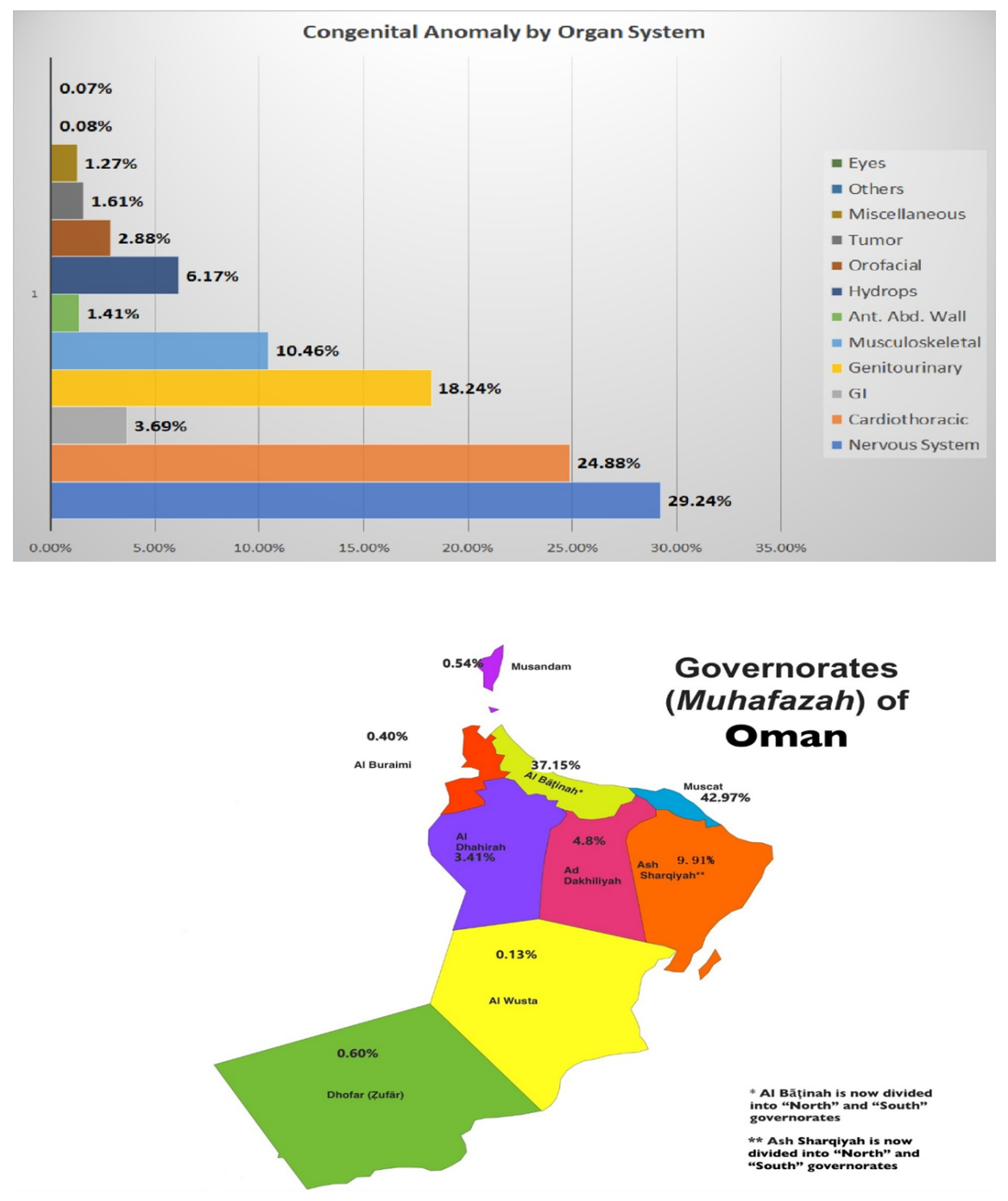